
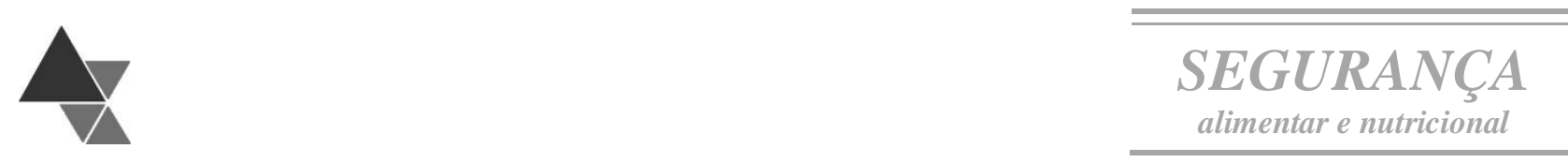

\title{
Ora-pro-nobis: saberes e novas oportunidades
}

\author{
Michelle Nogueira de Jesus ${ }^{1}$ e Juliana Teodora de Assis Reges ${ }^{2}$
}

Ora-pro-nobis (Pereskia aculeata Miller) é uma hortaliça não convencional que possui importante qualidade quanto ao teor de proteínas, mas não foi introduzida, de forma expressiva, na alimentação das pessoas no dia-a-dia. Dessa forma, o objetivo deste trabalho foi elaborar e avaliar, sensorialmente, dez produtos à base de ora-pro-nobis, sendo cinco da área salgada (arroz, macarrão, frango, pão e polenta) e cinco da área doce (bolo de chocolate, brigadeiro, bolo tradicional, pudim e sorvete). A pesquisa foi realizada no Laboratório de Processamento da Universidade Estadual de Goiás, Campus Jataí. A avaliação sensorial contou com a participação de 80 julgadores não-treinados. Foram utilizados dois testes durante a pesquisa: escala hedônica (notas 1 a 9) e a aceitação das características do produto (cor, aroma, sabor e textura). Observou-se, na análise sensorial, por meio da escala hedônica e das características que as receitas 001, 002, 003, 005, A, B, C e D, tiveram maior aceitação pelos julgadores. Contudo, das dez receitas, apenas a receita 004, não atingiu o índice de aceitabilidade (maior que $70 \%$ ), o que leva a classifica como a única amostra inviável para comercialização.

Palavras-chave: Pereskia aculeata Miller, Plantas Alimentícias, Análise sensorial, Aceitabilidade.

\section{Ora-pro-nobis: knowledge and new opportunities}

Ora-pro-nobis (Pereskia aculeata Miller) is an non-conventional vegetable that has a high quality protein content but has not been introduced to people's diet on a day-to-day basis. Thus, the objective of this work was to elaborate and evaluate, sensorially, ten products based on ora-pro-nobis, five of the salt area (rice, pasta, chicken, bread and polenta) and five of the sweet area, brigadeiro, traditional cake, pudding and ice cream). The research was carried out at the Processing Laboratory of the State University of Goiás, Campus Jataí. Sensory evaluation was attended by 80 untrained judges. Two tests were used during the research: hedonic scale (grades 1 to 9) and acceptance of product characteristics (color, aroma, flavor and texture). It was observed in the sensorial analysis, through the hedonic scale and the characteristics that the recipes 001, 002, 003, 005, A, B, C and D, were more accepted by the judges. However, of the 10 recipes, only the 004 revenue, did not reach the acceptance rate higher than $70 \%$, which makes it the only sample that is unfeasible for commercialization.

Keywords: Pereskia aculeata Miller, Food Plants, Sensory Analysis, Acceptability.

${ }^{1}$ Discente do Curso Superior em Tecnologia em Alimentos, da Universidade Estadual de Goiás - Campus Jataí.

2 Professora Doutora em Agronomia, Docente do Curso Superior em Tecnologia em Alimentos e Coordenadora Adjunta de Pesquisa - Universidade Estadual de Goiás Campus Jataí. Endereço para correspondência: Rua Léo Lince no 610 - S Samuel Grahan, Jataí - GO - CEP: 75800-000 - E-mail: juliana.reges@ueg.br 


\section{INTRODUÇÃO}

A alimentação saudável é um dos primórdios da vida e depende diariamente de alimentos nutritivos. No entanto, a população desperdiça alimentos por não conhecer totalmente seus benefícios, não fazendo assim o aproveitamento dos seus nutrientes ${ }^{[1]}$. Perante a isso, acabam buscando por alimentos mais rápidos, onde acabam ingerindo alimentos gordurosos e ricos em açúcares, os quais são considerados fontes de teor baixo em relação a nutrientes. O modelo fast food transformou-se em um sinônimo de estilo de vida, em que o tempo é exíguo até mesmo para a realização das refeições[2].

Dessa forma, com o passar dos anos as indústrias apresentaram uma evolução na produção de alimentos convencionais, e a população aumentou o consumo destes, levando à redução de ingestão de frutas e hortaliças ${ }^{[3]}$.

Porém, mesmo com essa evolução e apesar de serem alimentos com fontes alimentares saudáveis, às frutas e hortaliças não são sempre acessíveis a todos ou a maioria não faz o uso, por opção. Além disso, podem ser encontradas em locais domiciliares, em terrenos baldios, quintais e jardins, mas poucos têm o conhecimento sobre o seu valor nutricional e do seu fácil cultivo[4].

Diante disso, autores implementado pesquisas no sentido de buscar a identificação da composição para a viabilidade da recomendação dos alimentos não convencionais como alternativa de consumo. Dentre esses alimentos, destaca-se a hortaliça não convencional ora-pro-nobis (Pereskia aculeata Miller), pertencente à família cactácea, conhecida popularmente como carne - de- pobre. A hortaliça é rica em vitaminas $A, B, C$, fibras, ferro e fósforo, são nutrientes fundamentais para o organismo humano[4].

Com relação aos valores nutricionais da folha, $100 \mathrm{~g}$ de Pereskia aculeata Miller possuem aproximadamente 22,9 g de proteína, 3,6 g de lipídeos, $36,2 \mathrm{~g}$ de carboidrato e $12,6 \mathrm{~g}$ de fibras totais [3]. A necessidade diária de ferro para um homem adulto está em torno de $10 \mathrm{mg} /$ dia e para mulheres adultas, essa necessidade é próxima a $15 \mathrm{mg} /$ dia. Portanto a ora-pro-nobis tem potencial para contribuir com as necessidades diárias deste mineral, tanto para homens quanto para as mulheres ${ }^{[10]}$.

Um alimento além de seu valor nutritivo deve trazer satisfação e ser agradável ao consumidor, isto é resultante do equilíbrio de diferentes parâmetros de qualidade sensorial. A análise sensorial é definida como a disciplina científica usada para evocar, medir, analisar e interpretar reações das características dos alimentos e materiais como são percebidas pelos sentidos da visão, olfato, gosto, tato e audição[5]. As folhas de ora-pro-nobis, podem ser usadas em receitas como sopas, omeletes, tortas e refogadas, ou ainda cruas em saladas ${ }^{[4]}$.

Assim, os autores do trabalho objetivaram a elaboração de dez receitas para o dia-a-dia, considerando a classificação de dois grupos, a saber: salgados (macarrão, arroz, frango, pão, polenta) e a doces (bolo de chocolate, pudim, sorvete, brigadeiro, bolo tradicional), com agregação de maior valor nutricional, utilizando a hortaliça ora-pro-nobis, e avaliação da aceitação das mesmas por meio de análise sensorial com participantes não-treinados no município de Jataí (Goiás).

\section{METODOLOGIA}

O trabalho foi dividido em três etapas: A primeira etapa consistiu na escolha das folhas e a preparação da farinha de ora-pro-nobis. A segunda etapa envolveu o preparo dos dez produtos alimentícios, de sabores variados utilizando as partes da ora-pro-nobis, (o talo, folha, farinha). Por último, foi realizada uma pesquisa de percepção sensorial dos produtos fabricados.

\section{Coletas das Amostras}

As amostras de ora-pro-nobis, foram coletadas no município de Jataí (Goiás), sendo selecionadas de acordo com aparência e depois lavadas.

\section{Preparo das Receitas}

Os ingredientes para formulação básica das receitasforam adquiridos em comércios atuantes no 
município, observando-se o prazo de validade. Foirealizado o processamento dos seguintes alimentos: salgados (o macarrão, arroz, frango, pão, polenta) e doces (bolo de chocolate, pudim, sorvete, brigadeiro, bolo tradicional). As receitas podem ser examinadas no final do trabalho(Anexo). As receitas, contaram com as folhas verdes e farinha de Pereskia aculeata Miller (ora-pro-nobis).

As folhas da hortaliça utilizadas no processamento foram lavadas em água corrente e imersas em solução de $200 \mu \mathrm{L}$ de hipoclorito de sódio por litro de água destilada, por 10 minutos, lavada novamente em água corrente. Algumas folhas foram submetidas a desidratação na estufa em temperatura de $65^{\circ} \mathrm{C}$ e após 12 horas as folhas foram retiradas, trituradas, obtendo-se a farinha.

O pão, bolo de chocolate, pudim, sorvete, brigadeiro, bolo tradicional, foram produzidos um dia antes da análise sensorial, sendo armazenados na geladeira a uma temperatura de $5^{\circ} \mathrm{C}$. O macarrão, arroz, frango e a polenta foram preparados no mesmo dia da análise sensorial.

As receitas foram preparadas no Laboratório de Processamento de Alimentos da Universidade Estadual de Goiás - Campus de Jataí. Os responsáveis pelo preparo das receitas utilizaram os Equipamentos de Proteção Individual (EPI's) como calçados e botas fechados, jalecos, máscaras, toucas e luvas.

\section{Análise Sensorial}

Após processamento, os alimentos foram usados nos testes de avaliação sensorial, por 80 provadores (ambos os sexos), discentes dos Cursos de Tecnologia em Alimentos e Logística da Universidade Estadual de Goiásnão treinados, escolhidos aleatoriamente.

A análise sensorial foi realizada no período noturno, durante o horário dos cursos, havendo anuência dos coordenadores para a liberação dos alunos para a participação dos alunos nos testes de análise sensorial. A pesquisa recebeu aprovação do Comitê de Ética de Pesquisa - CEP da Universidade Estadual de Goiás (processo no 72560217.8.0000.8113). Para cada julgador, foi entregue duas vias do termo de Consentimento Livre e
Esclarecido (TCLE). Os provadores receberam as porções, de maneira aleatória, em pequenos pratos plásticos codificados.

Para caracterização dos colaboradores e aceitação global, foi utilizada a escala hedônica, onde cada provador atribuiu uma nota de 1 a 9 na aceitação global, sendo a nota 1 representando a opção "desgostei extremamente" e a 9, "gostei extremamente" (Quadro 1). A ficha de avaliação contou com um questionário de coleta de dados contendo as variáveis sexo e hábitos de consumo referentes ao produto base e ora-pro-nobis.

Para aceitação dos novos pratos, o participante atribuiu notas de 0 a $100 \%$ em relação às receitas de acordo com as características dos produtos, tais como, cor, sabor, aroma e textura (Quadro 2). As receitas foram apresentadas em pratos codificados em amostra 001, amostra 002, amostras 003, amostra 004, e amostra 005 para os alimentos salgados. Já os pratos doces, foram codificados em amostra A, amostra B, amostra C, amostra D e amostras E.

Quadro 1. Modelo da ficha para caracterização dos colaboradores e aplicação do Teste com Escala Hedônica

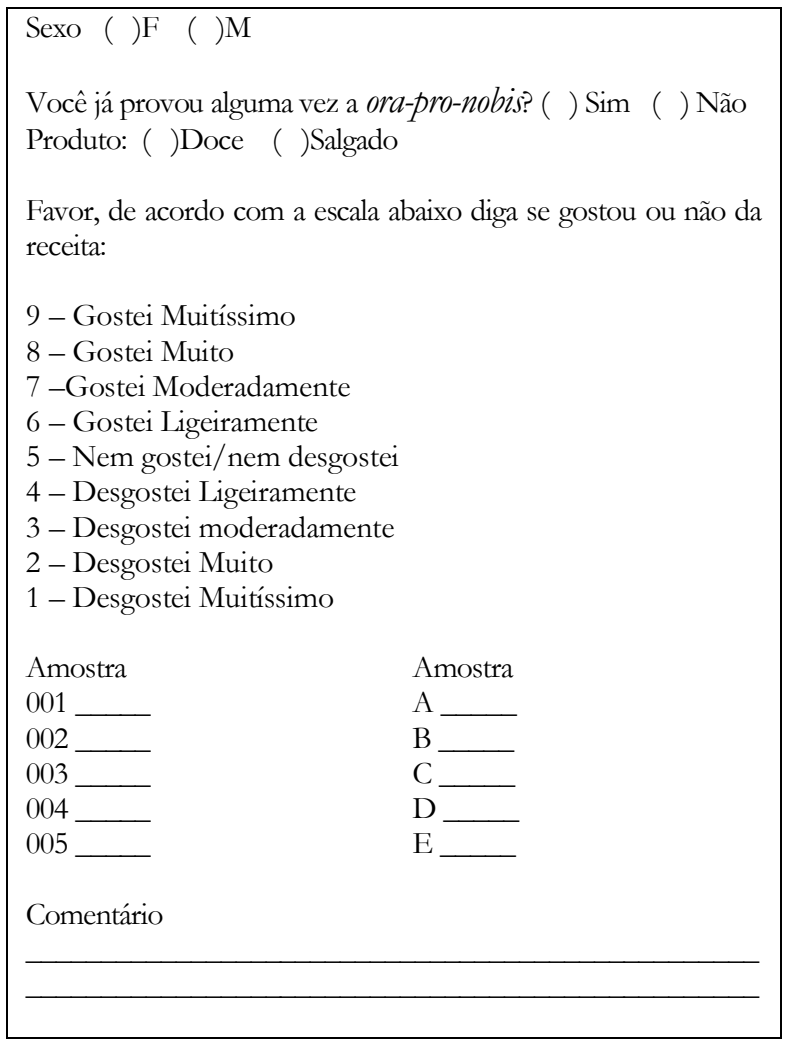


Quadro 2. Avaliação das características do produto

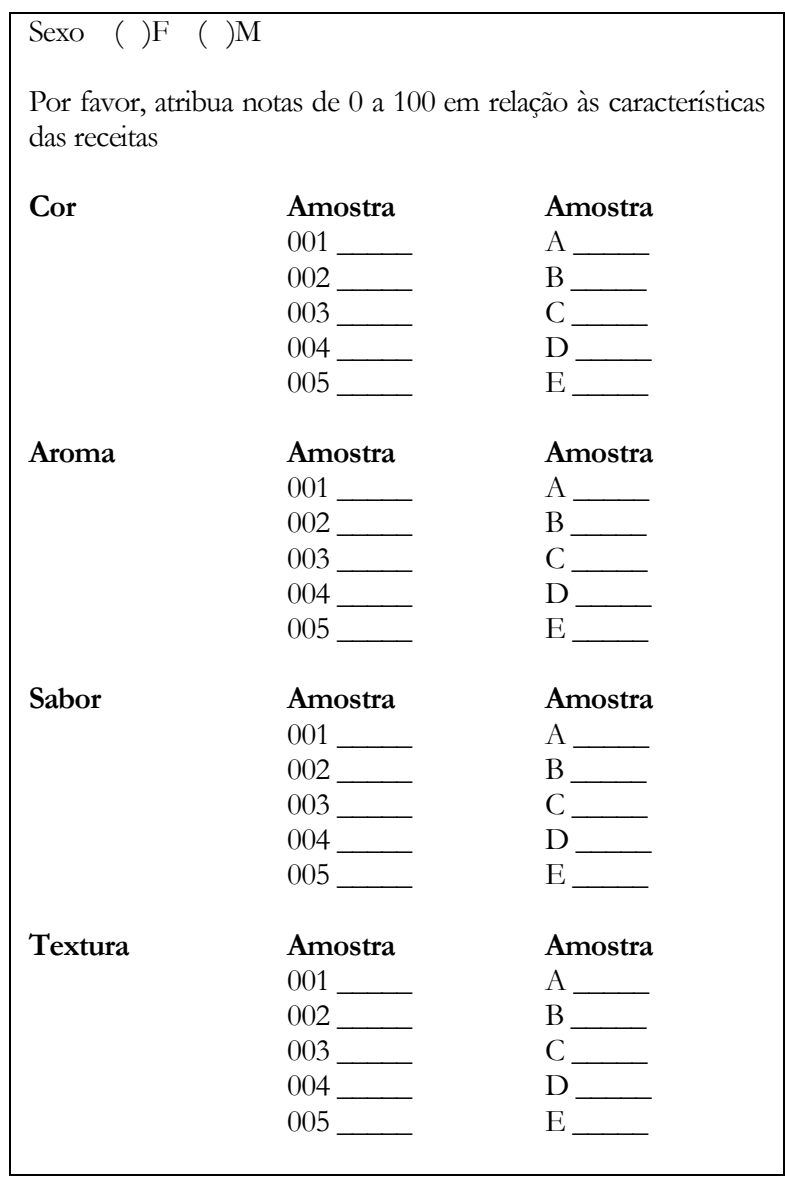

\section{ANÁLISES ESTATÍSTICAS}

Os resultados foram analisados e o cálculodas médias e desvios padrão obtido por meio de planilha Excel 2007®. O Índice de Aceitabilidade (IA) foi calculado a partir da expressão IA $(\%)=\mathrm{A} \times 100 / \mathrm{B}$, onde A é a média obtida para o produto e $\mathrm{B}$ a nota máxima atribuída ao produto.

\section{RESULTADOS E DISCUSSÃO}

Oitenta julgadores não-treinados, sendo maioria $(63,8 \%)$ do sexo feminino, participaram do teste. Devido à análise sensorial ter sido realizada em uma universidade, a maioria dos entrevistados tinha idade entre 18 e 60 anos. Dos resultados obtidos em relação à frequência sobre já ter consumido ora-pronobis alguma vez, somente $7,5 \%$ dos entrevistados afirmaram terem a experiência de consumo de Pereskia aculeata Miller, enquanto que $80 \%$ nunca provaram e
$12,5 \%$ dos candidatos não responderam o questionamento.

Diante disso, verificou-se que poucas são as pessoas que conhecem a hortaliça Pereskia aculeata Miller e sua importância em relação à alimentação. $\mathrm{O}$ seu valor nutricional ainda é desconhecido pela maior parte da população[6]. De maneira geral, esta falta de conhecimento é uma das principais razões para a não utilização dessas hortaliças.

Em relação aos alimentos produzidos com as folhas de Pereskia aculeata Miller (Tabela 1). As receitas salgadas foram codificadas em números, sendo 001 (arroz), 002 (macarrão), 003 (frango de molho), 004 (pão) e 005 (polenta). Já as codificações das receitas doces seguiram por letras: A (bolo de chocolate), B (brigadeiro), C (bolo tradicional), D (pudim) e E (sorvete), totalizando dez receitas com inclusão das folhas e farinhas de ora-pro-nobis.

Tabela 1. Produtos alimentícios elaborados com inclusão de folhas e farinhas de Pereskia aculeata Miller

\begin{tabular}{lc}
\hline \multicolumn{2}{c}{ Tipo } \\
\hline Arroz & Codificação recebida \\
Macarrão & 001 \\
Frango & 002 \\
Pão & 003 \\
Polenta & 004 \\
Bolo de chocolate & 005 \\
Brigadeiro & $\mathrm{A}$ \\
Bolo tradicional & $\mathrm{B}$ \\
Pudim & $\mathrm{C}$ \\
Sorvete & $\mathrm{D}$ \\
\hline
\end{tabular}

Os resultados da análise sensorial para os diferentes produtos salgados, foram reunidos na Tabela 2.

A análise das amostras, em geral, revelou média de $8 \pm 1,9$. Observa-se, para a receita 001, que $39 \%$ dos avaliadores atribuíram a nota 9 ("gostei muitíssimo") da escala hedônica e a segunda nota mais atribuída foi a 36,6\% ("gostei muito") totalizando $75,6 \%$ dos avaliadores que gostaram dessa receita. Já para a receita 002 , prevaleceu a atribuição da nota 8 ("gostei muito"); com porcentagem 33\%, seguida da nota 9 ("gostei muitíssimo") que recebeu $29 \%$ da indicação dos avaliadores, a menor nota atribuída foi 5 (4\%). Para a receita 003, a nota mais atribuída também foi a $9(50 \%)$-“gostei muitíssimo", seguida da nota 8 
("gostei muito") que recebeu $24 \%$ da indicação dos avaliadores. A receita 004 recebeu de forma majoritária a nota 7 (24\%) -"gostei moderadamente", seguida da nota 9 ("gostei extremamente") que recebeu 19\% da indicação dos avaliadores, seguido das notas 4 (“desgostei ligeiramente") e 5 (11\%) - “nem gostei/nem desgostei”. Para a receita 005 , prevaleceu a atribuição da nota 9 (40\%)-“gostei muitíssimo", sendo seguida pela nota $8(19 \%)$ "gostei muito" e nota 3 $(10 \%)$ ("desgostei moderadamente").

Tabela 2.Distribuição da frequência, média, mínimo, máximo e desvio padrão da escala hedônica dos produtos salgados a base de ora-pro-nobis

\begin{tabular}{|c|c|c|c|c|c|c|c|c|c|c|}
\hline \multicolumn{11}{|c|}{ Valores } \\
\hline & & & & & & & Desv & & & \\
\hline \multirow{2}{*}{ Escala Hedônica } & $\mathrm{n}$ & $\%$ & $\mathrm{n}$ & $\%$ & $\mathrm{n}$ & $\%$ & $\mathrm{n}$ & $\%$ & $\mathrm{n}$ & $\%$ \\
\hline & \multicolumn{2}{|c|}{001} & \multicolumn{2}{|c|}{002} & \multicolumn{2}{|c|}{003} & \multicolumn{2}{|c|}{004} & \multicolumn{2}{|c|}{005} \\
\hline Gostei Muitíssimo & 31 & 39 & 23 & 29 & 40 & 50 & 15 & 19 & 32 & 40 \\
\hline Gostei Muito & 29 & 36 & 26 & 33 & 19 & 24 & 6 & 8 & 15 & 19 \\
\hline Gostei Moderadamente & 14 & 18 & 15 & 19 & 12 & 15 & 19 & 24 & 9 & 11 \\
\hline Gostei Ligeiramente & 5 & 6 & 7 & 9 & 5 & 6 & 6 & 8 & 9 & 11 \\
\hline Nem Gostei/Nem Desgostei & 1 & 1 & 4 & 5 & 2 & 3 & 11 & 14 & 2 & 3 \\
\hline Desgostei Ligeiramente & 0 & 0 & 2 & 3 & 0 & 0 & 11 & 14 & 2 & 3 \\
\hline Desgostei Moderadamente & 0 & 0 & 3 & 4 & 1 & 1 & 5 & 6 & 8 & 10 \\
\hline Desgostei Muito & 0 & 0 & 0 & 0 & 1 & 1 & 6 & 8 & 1 & 1 \\
\hline Desgostei Muitíssimo & 0 & 0 & 0 & 0 & 0 & 0 & 1 & 1 & 2 & 3 \\
\hline
\end{tabular}

$*_{\mathrm{n}}=$ número de julgadores

De maneira geral, os resultados demonstraram que houve uma boa aceitação sensorial quanto às receitas 001, 002, 003 e 005. A receita 004, segundo os avaliadores, encontrava-se com aspecto duro, e seu sabor não era característico de pão, alcançando a 58\% de aceitação. Essa percepção pode ser esclarecida pelas características da farinha utilizada no preparo que atribuiu ao pão uma coloração esverdeada, o que pode ter interferido na sua aceitabilidade. A mesma coloração foi encontrada na massa do macarrão elaborado com as plantas, devido à presença de pigmentos verdes.

Quanto à percepção sensorial dos produtos doces, observa-se, que a média geral atribuída $7,7 \pm 1,7$ (Tabela 3).

Tabela 3.Distribuição da frequência, média, mínimo, máximo e desvio padrão da escala hedônica dos produtos doces a base de ora-pro-nobis

\begin{tabular}{|c|c|c|c|c|c|c|c|c|c|c|}
\hline \multicolumn{11}{|c|}{ Valores } \\
\hline & & & & & & & Desv & & & \\
\hline \multirow{2}{*}{ Escala Hedônica } & $\mathrm{n}$ & $\%$ & $\mathrm{n}$ & $\%$ & $\mathrm{n}$ & $\%$ & $\mathrm{n}$ & $\%$ & $\mathrm{n}$ & $\%$ \\
\hline & \multicolumn{2}{|c|}{ A } & \multicolumn{2}{|c|}{ B } & \multicolumn{2}{|c|}{$\mathrm{C}$} & \multicolumn{2}{|c|}{$\mathrm{D}$} & \multicolumn{2}{|c|}{$\mathrm{E}$} \\
\hline Gostei Muitíssimo & 36 & 45 & 37 & 46 & 35 & 44 & 46 & 58 & 21 & 26 \\
\hline Gostei Muito & 23 & 29 & 25 & 31 & 13 & 16 & 18 & 23 & 10 & 13 \\
\hline Gostei Moderadamente & 13 & 16 & 9 & 11 & 13 & 16 & 5 & 6 & 15 & 19 \\
\hline Gostei Ligeiramente & 5 & 6 & 5 & 6 & 9 & 11 & 3 & 4 & 8 & 10 \\
\hline Nem Gostei/Nem Desgostei & 2 & 3 & 2 & 3 & 5 & 6 & 1 & 1 & 9 & 11 \\
\hline Desgostei Ligeiramente & 0 & 0 & 1 & 1 & 3 & 4 & 3 & 4 & 4 & 5 \\
\hline Desgostei Moderadamente & 0 & 0 & 0 & 0 & 1 & 1 & 2 & 3 & 5 & 6 \\
\hline Desgostei Muito & 0 & 0 & 0 & 0 & 0 & 0 & 1 & 1 & 3 & 4 \\
\hline Desgostei Muitíssimo & 0 & 0 & 0 & 0 & 0 & 0 & 0 & 0 & 4 & 5 \\
\hline
\end{tabular}


Para a receita A, nota-se que $45 \%$ dos avaliadores atribuíram a nota 9 ("gostei muitíssimo") e a segunda nota mais atribuída foi a 8, 29\% ("gostei muito"), seguida da nota 7 (gostei moderadamente") com 16\%, totalizando $69,3 \%$ dos avaliadores que gostaram dessa amostra; a nota menos citada pelos julgadores foi a 5 (6\%)- "não gostei/nem desgostei. Já para a receita $\mathrm{B}$, a nota prevalecente foi a $9(46 \%)$ "gostei extremamente", seguida da nota 8 (31\%)("gostei muito") que recebeu 31\% da indicação dos avaliadores, seguido da nota 7 (11\%)"gostei moderadamente", com 11\%, tendo $89 \%$ de aceitação. Para a receita $C$, a nota a sequência de atribuições foi: 9 ("gostei muitíssimo"), com percentual de 44\%, seguida da nota 8 ("gostei muito") e 7 (gostei moderadamente), ambas receberam 16\% da indicação dos avaliadores, atingindo um percentual de aceitação de $76 \%$. Para a receita $\mathrm{D}$, a nota mais atribuída também foi a 9 (58\%) -"gostei muitíssimo", seguida da nota 8 ("gostei muito") que recebeu $23 \%$ e depois a nota 7 ("gostei moderadamente"), com 6\%. Para a receita E, prevaleceu as seguintes atribuições: 9 (26\%) "gostei muitíssimo", considerada a menor percentagem,seguida da nota 7 ("gostei moderadamente") que recebeu $19 \%$, seguida da amostra 8 (gostei muitíssimo) com 13\%.

Tendo por base os resultados obtidos tanto para as receitas (salgadas e doces), as notas foram muito altas para os produtos, com destaque para as receitas 004 e E. Os resultados obtidos em relação às características dos produtos, como cor, aroma, sabor e textura estão apresentados na Tabela 4.

Tabela 4. Resultados de medias e desvio padrão referente à avaliação da cor, aroma, sabor e textura dos produtos salgados e doces a base de ora-pro-nobis

\begin{tabular}{c|ccccccccccccc}
\hline \multicolumn{10}{c}{ Características do Produto } \\
\hline Receitas & \multicolumn{4}{c}{ Cor } & \multicolumn{3}{c|}{ Aroma } & \multicolumn{4}{c}{ Sabor } & \multicolumn{3}{c}{ Textura } \\
\hline 001 & 92 & \pm & 10,4 & 88 & \pm & 14,54 & 88 & \pm & 17,89 & 88 & \pm & 19,46 \\
002 & 83 & \pm & 17,5 & 83 & \pm & 17,44 & 82 & \pm & 19,39 & 85 & \pm & 18,00 \\
003 & 89 & \pm & 15,6 & 87 & \pm & 17,16 & 84 & \pm & 21,99 & 86 & \pm & 20,53 \\
004 & 74 & \pm & 20,1 & 74 & \pm & 22,79 & 67 & \pm & 28,13 & 69 & \pm & 29,57 \\
005 & 85 & \pm & 21,6 & 84 & \pm & 20,84 & 79 & \pm & 24,87 & 80 & \pm & 23,34 \\
A & 90 & \pm & 16,0 & 87 & \pm & 14,67 & 84 & \pm & 18,24 & 88 & \pm & 16,65 \\
B & 92 & \pm & 13,4 & 88 & \pm & 14,66 & 89 & \pm & 13,37 & 86 & \pm & 19,01 \\
C & 88 & \pm & 15,8 & 83 & \pm & 19,82 & 80 & \pm & 23,45 & 86 & \pm & 19,70 \\
D & 86 & \pm & 21,4 & 80 & \pm & 24,55 & 82 & \pm & 26,95 & 85 & \pm & 24,25 \\
E & 70 & \pm & 30,2 & 67 & \pm & 31,37 & 63 & \pm & 33,44 & 62 & \pm & 34,71 \\
\hline
\end{tabular}

Há indícios de forte aceitação dos produtos oferecidos, uma vez que o índice de aceitabilidade (Tabela 5) foi maior que $70 \%$ para a maioria dos produtos. O índice de aceitabilidade a partir de $70 \%$ já é suficiente para considerar o produto "aceito" [7].

As análises conjuntas dos dados em relação ao índice de aceitabilidade referente às características dos produtos mostraram que as receitas 001, 002, 003, 005; A, B, C e D obtiveram expressivo percentual (acima de 80\%), e as receitas 004 e E com valões inferiores a $70 \%$.
Já em relação ao índice de aceitabilidade de acordo com a escala hedônica, somente a receita 004 , não conquistou aceitabilidade por parte dos julgadores, com percentual de $69 \%$. Este resultado pode estar associado ao fato de as pessoas esperarem características parecidas com os pães tradicionais. Provavelmente o que influenciou nos resultados negativos, foram os atributos de sabor, textura e cor. 
Tabela 5. Índice de aceitabilidade (expresso em percentagem) dos produtos com adição de ora-pro-nobis

\begin{tabular}{c|c|c|c|c|c}
\hline \multicolumn{7}{c}{ Índice de Aceitabilidade } \\
\hline Receitas & Cor & Aroma & Sabor & Textura & $\begin{array}{c}\text { Escala } \\
\text { Hedônica }\end{array}$ \\
\hline 001 & 92 & 88 & 88 & 88 & 89 \\
002 & 83 & 83 & 82 & 85 & 83 \\
003 & 89 & 87 & 84 & 86 & 89 \\
004 & 74 & 74 & 67 & 69 & 67 \\
005 & 85 & 84 & 79 & 80 & 79 \\
A & 90 & 87 & 84 & 88 & 90 \\
B & 92 & 88 & 89 & 86 & 90 \\
C & 88 & 83 & 80 & 86 & 85 \\
D & 86 & 80 & 82 & 85 & 89 \\
E & 70 & 67 & 63 & 62 & 71 \\
\hline
\end{tabular}

A respeito de estudos que elaboraram produtos alimentícios a partir de alimentos não convencionais, observaram-se, entre os consumidores distintos resultados referentes à aceitabilidade dos pratos. Em um estudo realizado com adição de ora-pronobis desidratada ao macarrão (adição de $2 \%$ da planta), obteve-se um índice de aceitabilidade de $92 \%$, demonstrando que pequenas concentrações adicionadas em preparações alimentícias são mais bem aceitas pelos consumidores ${ }^{[8]}$.

Já em outro estudo, em relação à aceitação global, o pão com bertalha apresentou nota 6,17 e o pão com ora-pro-nobis, nota 7[4]. Dessa forma, para o alcance de uma boa aceitabilidade do pão a base de farinha de ora-pro-nobis, será necessário o desenvolvimento de maior número de estudos visando a identificação da quantidade máxima e mínima de farinhas ou folhas a passiveis de serem acrescentadas, para que os produtos e/ou preparações sejam bem aceitos pelos consumidores.

Por meio de um estudo que envolveu a incorporação da ora-pro-nobis em dez produtos convencionais alimentícios, foi obtido índice de aceitabilidade maior que $90 \%$ para todos os produtos ${ }^{[9]}$. Portanto, a adição de ora-pro-nobis como fonte de nutriente na alimentação diária pode ser opção viável, estimulando também a ampliação do seu cultivo.

\section{CONCLUSÕES}

A partir dos resultados obtidos, nota-se que somente a receita 004 (pão), é uma alternativa inviável para a comercialização, devido ao seu índice de aceitação ser inferior a 70\%. A adição da folha orapro-nobis, pode ser implementada na alimentação dos seres humanos, uma vez que poderá alcançar satisfatória aceitabilidade. A planta pode ser uma ótima opção na alimentação dos seres humanos, principalmente para as pessoas de baixa renda e aquelas que almejam por uma alimentação mais saudável.

\section{REFERÊNCIAS}

[1] PAS - Programa Alimentos Seguros. Banco de Alimentos e Colheita Urbana: Aproveitamento Integral dos Alimentos. Rio de Janeiro: SESC/DN; 2003.

[2] Silva RS. Treinamento e Qualidade: um estudo do treinamento e capacitação dos colaboradores do Mcdonalds (Natal/RN) [monografia]. Natal: Universidade Federal do Rio Grande do Norte; 2013.

[3] Almeida MEF. Farinha de folhas de cactáceas do gênero Pereskia: caracterização nutricional e efeito sobre ratos wistar submetidos à dieta hipercalórica[tese]. Lavras: Universidade Federal de Lavras; 2012.

[4] Martinevski CS, Oliveira VR, Rios AO, Flores SH, Venzke JG. Utilização de Bertalha (Anrederacordifolia (Ten.) Steenis) e Ora-Pro-Nobis (Pereskiaaculeata Mill.) na elaboração de pães. BrazilianjournalFoodandNutrition. 2013;24:255-370.

[5] ABNT -Associação Brasileira de Normas Técnicas. Análise sensorial dos alimentos e bebidas: terminologia. São Paulo: ABNT; 1993.

[6] Paula MC, OliveiraRB, FelipeDF, Magrine ICO, SARTOR CFP. Processamento de bolo com a planta Pereskiaaculeata Mill. (Ora-pro-nobis). Revista Brasileira de Produtos Agroindustriais. 2016;18(2):167-174.

[7] Oliveira DM, Marques D, Kwiatkowski A, Monteiro ARG, Clemente E. Sensory analysis and chemical characterization of cereal enriched with grape peel and seed flour. Acta Scientiarum Technology. 2013;35(3):427-431.

[8] Rocha DRC, Pereira Júnior GA, Vieira G, PantojaL, Santos AS, Pinto NAVD.Macarrão adicionado de ora-pronobis (Pereskiaaculeata Miller) desidratado. Alimentos e Nutrição. 2008;19(4):459-465.

[9] Queiroz CRAAQ, Ferreira L, Gomes LBP, Melo CMT,Andrade RR. Ora-pro-nobis em uso alimentar humano: 
percepção sensorial.Revista Verde de Agroecologia e Desenvolvimento Sustentável. 2015;10:01-05.

[10] Girão LVC, Silva Filho JC, Pinto JEBP, Bertolucci SKV. Avaliação da Composição Bromatológica de Ora-pronobis. Lavras: Universidade Federal de Lavras; 1997. 


\section{ANEXO}

\section{RECEITAS SALGADAS}

\section{RECEITA 1 - ARROZ}

Ingredientes:óleo a gosto,sal a gosto,três xícaras de arroz,2 alhos amassados,folhas de ora-pro-nobis.

Modo de preparo: em uma panela doure o alho; em seguida acrescente o arroz e deixe-o cozinhar. Pique as folhas de ora-pro-nobis em tiras como se fosse couve. Em uma panela refogue a mesma, e quando o arroz tiver pronto misture-a no meio.

\section{RECEITA 2 - MACARRÃO COM MOLHO DE ORA-PRO-NOBIS}

Ingredientes: $250 \mathrm{~g}$ de macarrão parafuso.

Para o molho: $300 \mathrm{~g}$ de folhas de ora-pro-nobis, alho cortado em fatias (a gosto), cebola em rodelas (a gosto).

Modo de preparo:

Macarrão: cozinhar o macarrão em água, óleo e sal e deixar cozinhar até que fique no ponto ao dente. Após o cozimento não jogar água fria, apenas deixar escorrer e reservar em refratário.

Molho: dourar o alho com um pouco de óleo e deixar fritar por pouco tempo apenas para pegar um douradinho. Para preparar as folhas de ora-pro-nobis deixe as folhas de molho no vinagre de 3 a 5 minutos; após esse tempo escorrer e jogar água corrente. Leve ao liquidificador com $400 \mathrm{~mL}$ de água quente e bata tudo. Jogue este molho na frigideira com o alho e a cebola dourada e deixe cozinhar; quando levantar fervura conte 3 minutos e despeje por cima do macarrão.

\section{RECEITA 3 - FRANGO}

Ingredientes: 1 frango limpo, cortado e temperado, 1/4 de xícara de azeite, 1 tablete de caldo de galinha (preferência caipira), 2 dentes de alho picados em pequenos pedaços, 2 cebolas cortadas em pedaços médios, suco de $1 / 2$ limão pequeno, 20 folhas de ora-pro-nobis, sal a gosto.

Modo de preparo: junte em uma panela o azeite, o suco de 1/2 limão e os pedaços de frango, mexa em fogo médio até que o frango comece a dourar; em seguida acrescente os dentes de alho picadinhos e mexa por mais alguns minutos. Após dourar levemente os pedaços de frango retire o excesso de gordura da panela, acrescente as cebolas, misturando-as aos pedaços de frango, coloque o caldo de galinha e acrescente água quente, aos poucos, em pequenas quantidades, até que o frango cozinhe.Após o frango cozido, espalhe as folhas de ora-pro-nobis por cima do frango, sem mexer ou misturar, de maneira a cobrir o caldo de folhas. Tampe bem a panela e deixe cozinhar em fogo baixo por mais ou menos cinco minutos. 


\section{RECEITA 4 - PÃO CASEIRO COM FARINHA DE ORA-PRO-NOBIS}

Farinha: lave algumas folhas de ora-pro-nobis em água potável, deixe-as imersas em solução de $200 \mathrm{~mL}$ de hipoclorito de sódio por litro de água destilada, por 10 minutos; lave novamente em água corrente. Em seguida submeta as folhas à desidratação em temperatura de $65^{\circ} \mathrm{C}$, após 12 horas, triture-as, obtendo-se a farinha.

Ingredientes do pão:50 g de fermento para pão, 1/2 copo de água morna,1/2 copo de água fria,2 colheres (sopa) de margarina, 2 ovos inteiros, 1 colher (sopa) rasa de açúcar,1 colher (sobremesa) de sal, $500 \mathrm{~g}$ de farinha ora-pro-nobis (pode ir um pouco mais ou menos, dependendo do ponto da massa).

Modo de preparo: dissolva o fermento juntamente com açúcar na água morna. Misture em seguida os ovos, a margarina e o sal e reserve. Junte aos ingredientes reservados, adicionando a farinha até que a massacomece a soltar das mãos.Sove bem e deixe descansar até que dobre de volume. Divida a massa em dois pães e coloque novamente para crescer.Leve para assar em forno já aquecido.

\section{RECEITA 5 -POLENTA}

Para o angu: $400 \mathrm{~g}$ de fubá mimoso,3 xícaras de água (temperatura ambiente),1 colher (café) de sal,1 colher (sopa) de óleo.

Para o molho: 1 colher (sopa) de óleo para refogar a carne,300 g de músculo moído,3 colheres de extrato de tomate,1 tablete de caldo de carne (ou bacon), cebola, cebolinha e salsa a gosto.

Montar prato intercalado: $200 \mathrm{~g}$ de muçarela ralada e $200 \mathrm{~g}$ de ora-pro-nobis (refogado).

Modo de preparo:

Molho: em uma panela refogue a carne moída até começar a fritar. Adicione os demais ingredientes do molho, deixe ferventar por 2 minutos e misture às vezes. Reserve.

Angu: coloque todos os ingredientes para o preparo do angu em uma panela e misture até o fubá ficar bem diluído. Leve ao fogo misturando sempre. Quando começar a borbulhar, continue mexendo por mais um minuto e desligue.

Ora-pro-nobis: corte como preferir o ora-pro-nobis e o refogue com meio copo de água (sem tempero). Reserve.

Montagem: em uma travessa faça camadas, começando com o angu, depois o molho, em seguida o queijo e por último o ora-pro-nobis.

\section{RECEITAS DOCES}

\section{RECEITA A - BOLO DE CHOCOLATE}

Ingredientes: 4 ovos, 4 colheres (sopa) de chocolate em pó,2 colheres (sopa) de manteiga,3 xícaras (chá) de farinha de trigo,2 xícaras (chá) de açúcar, 2 colheres (chá) de fermento, 1 xícara (chá) de leite. 
Modo de preparo: para o processamento do bolo primeiramente misture no liquidificador o leite com a quantidade desejada de folhas verdes de ora-pro-nobis e separe. Em seguida, bata o açúcar e a margarina por 10 minutos na batedeira até obter um creme homogêneo e claro. Após, nesse creme adicione os ovos inteiros, em seguida coloque a farinha e o fermento. Por último acrescente o chocolate em pó alternando-o com o leite contendo OPN e deixe bater por mais 6 minutos em velocidade baixa. Por último coloque a massa em forma previamente untada com margarina e farinha de trigo e asse em forno convencional a $180^{\circ} \mathrm{C}$, por 30 a 40 minutos.

\section{RECEITA B - BRIGADEIRO}

Ingredientes: 1 caixa de leite condensado,meia colher (sopa) de margarina sem sal,5 colheres (sopa) de achocolatado ou 3 colheres (sopa) de chocolate em pó chocolate granulado (se preferir), 2 folhas de ora-pro-nobis.

Modo de preparo: em uma panela funda, acrescente o leite condensado, a margarina e o chocolate em pó e as folhas de ora-pro-nobis picadas bem pequenininhas. Cozinhe em fogo médio e mexa até que o brigadeiro comece a desgrudar da panela.

\section{RECEITA C - BOLO TRADICIONAL}

Ingredientes: 2 xícaras (chá) de farinha de trigo, 2 xícaras (chá) de açúcar refinado, 1 xícara (chá) de leite, 1 xícara (chá) de folhas ora-pro-nobis picadas, 2 colheres(sopa) de margarina, 2 ovos, 1 colher de fermento em pó.

Modo de preparo: na batedeira bata o ovo, o açúcar e depois acrescente a farinha. No liquidificador, bata a margarina e a ora-pronobis e acrescente junto à massa; logo bata tudo e despeje a massa na assadeira untada e enfarinhada.

\section{RECEITA D -PUDIM}

Ingredientes: 1 lata de leite condensado, 3 ovos, 1 xícara(chá) de ora-pro-nobis, $250 \mathrm{~mL}$ de leite, 1 xícara (chá) de açúcar.

Modo de preparo: rasgue as folhas de ora-pro-nobis e deixe ferver com água em uma panela por 5 minutos. Escorra as folhas e lave com água fria. Em um liquidificador, bata o ovo, o leite, o leite condensado e as folhas de ora-pro-nobis e bata por cinco minutos. Reserve. Em uma vasilha para pudim coloque o açúcar para caramelizar, e em seguida despeje o pudim por cima e leve-o ao banho Maria por 40 minutos ou mais, dependendo da velocidade do forno.

\section{RECEITA E - SORVETE}

Ingredientes: Ora-pro-nobis, leite frio, açúcar, liga neutra.

Modo de preparo: desidrate as folhas de ora-pro-nobis em uma panela de fundo grosso até que as folhas murchem completamente. Em seguida, bata as folhas em uma batedeira ou no liquidificador, por sete minutos, com o leite frio, açúcar e a liga neutra. Leve ao congelador por uma hora. 